$\angle$ Research Square

\section{Myeloid-derived Suppressor Cells in the Blood of Iranian COVID-19 Patients}

\author{
Esmaeil Mortaz \\ Shahid Beheshti University of Medical Sciences School of Medicine \\ Mehrnaz Movasaghi \\ University of California Los Angeles \\ Ali Bassir \\ University of California Los Angeles \\ Neda K.Dezfuli \\ Medical University of Dezful https://orcid.org/0000-0001-6627-2912 \\ Neda Dalil Roofchayee \\ Shahid Beheshti University of Medical Sciences School of Medicine \\ Hamidreza Jamaati \\ Shahid Beheshti University of Medical Sciences School of Medicine \\ Johan Garssen \\ utrecht university \\ lan M. Adcock ( $\square$ lan.adcock@imperial.ac.uk) \\ Imperial College London
}

\section{Research}

Keywords: MDSC, IL-8, COVID-19, peripheral blood

Posted Date: August 9th, 2021

DOI: https://doi.org/10.21203/rs.3.rs-762160/v1

License: (우 (i) This work is licensed under a Creative Commons Attribution 4.0 International License. Read Full License 


\section{Abstract}

Background: A cytokine storm and lymphopenia are reported in coronavirus disease 2019 (COVID-19). Myeloid-derived suppressive cells (MDSCs) exist in two different forms, granulocyte (G-MDSCs) and monocytic (M-MDSCs) that both suppress T-cell function. Serum IL-6 and IL-8 levels seem to correlate with the number of blood MDSCs.

Objective: In the current study we aimed to find MDSCs frequency in severe COVID-19 patients from Iran and their correlations with serum IL-8 levels.

Methods: 37 severe ( 8 on ventilation, 29 without ventilation) and 13 moderate COVID-19 patients together with 8 healthy subjects were enrolled at the Masih Daneshvari Hospital, Tehran-Iran between 10th April 2020-9th March 2021. Clinical and biochemical features, serum and whole blood were obtained. CD14, CD15, CD11b and HLA-DR expression on MDSCs was measured by flow cytometry.

Results: M-MDSCs $(P \leq 0.0001)$ and G-MDSCs $(P \leq 0.0001)$ frequency were higher in Iranian COVID-19 patients compared to healthy subjects. M-MDSC frequency was higher in non-ventilated compared to moderate COVID-19 subjects $(P=0.004)$. IL-8 levels were higher in patients serum with COVID-19 than in normal healthy subjects $(P=0.03)$. IL8 level was significant difference in ventilated, non-ventilated and moderate patients $(P=0.005)$. The frequency of $G-$ MDSCs correlated negatively with INR $(r=-0.39, \mathrm{P}=0.02)$.

Conclusion: Serum IL-8 levels did not correlate with the number of systemic MDSCs in COVID-19 patients. The highest levels of M-MDSCs were seen in the blood of severe non-ventilated patients. MDSC frequency in blood in the current study did not predict the survival and severity of COVID-19 patients.

\section{Introduction}

The fast outbreak of severe acute respiratory syndrome coronavirus 2 (SARS-CoV-2), infection since its recognition in Wuhan China in December 2019 has resulted in a pandemic disease (1). Clinical observations suggest that SARS-CoV-2 infection can range from an asymptomatic infection through a respiratory illness with a fever and a dry cough to a severe acute respiratory syndrome-like disease requiring ventilation. There is a high rate of human-to-human transmission $(2,3)$. In addition, the mortality rate reported in patients with severe COVID-19 in the ICU range from 50-65\% (4). One of the most challenging complications of severe SARS-CoV-2 infection is a respiratory pneumonia. The pathophysiology of severe diseases appears variable (5).

It is important to find markers that can predict the prognosis of COVID-19 disease. Immunological studies on two other coronavirus infections, SARS-COV1 and MERS-COV have shown that immune-based pathological mechanisms are responsible for disease severity. These pathological mechanisms include lymphopenia and unregulated immune responses (6-8). Understanding the mechanism(s) and immunological patterns observed in COVID-19 is necessary for the achieving high efficiency of therapeutic interventions. Myeloid derived suppressive cells (MDSCs) originated from myeloid-cell lineage and are a diverse group of relatively immature myeloid cells (9).

Several studies have described mechanisms of MDSCs mediated immune suppression (9). MDSCs are divided into granulocytic (G-MDSCs or PMN-MDSC) and monocytic (M-MDSCs). In normal healthy body immature myeloid cells (IMCs) produced in the bone marrow and then differentiate into mature granulocytes, macrophages or dendritic cells (DCs) [7]. MDSCs expansion were occur in cancer, sepsis, trauma, bone marrow transplantation and some autoimmune diseases due to the inflammation and insults causes suppression normal differentiation of IMCs to the mature myeloid cells. MDSCs- cause excessive suppression of certain T-cell function which is leads to high immune responses(9-11). G-MDSCs produce high levels of ROS and low levels of NO whilst the M-MDSC subset produce low levels of ROS and high levels of NO and both subsets produce arginase (12). MDSCs modulated cytokine production (13) and can promote cancer metastasis in humans and in animal models $(12,14)$.

However, MDSCs shows a beneficial role in acute inflammatory responses such as in dengue virus infection where they decrease the inflammation and the subsequent immune reaction mediated pathology (15). Studies have reported that G-MDSC and M-MDSC expansion occurs in the systemic circulation of mainly patients with severe COVID-19 $(7,16)$ but these changes require validation different cohort's of different ethnicity and genetic background. We hypothesised, that the frequency of MDSCs and the potential to induce immune suppression is associate with the severity of COVID-19 disease in Iranian subjects. Thus, we studied the frequency of M-MDSCs and G-MDSCs in the systemic circulation of in moderate and severe Iranian COVID-19 patients and determined whether this was associated with systemic inflammation as reflected by IL-8 levels.

\section{Materials And Methods}

\section{Patients}

Fifty confirmed COVID-19 patients including 8 severe patients on ventilation, 29 severe non-ventilated and 13 moderate patients were participated into the study upon admission to the Masih Daneshvari Hospital of Shahid Beheshti Medical University (Tehran-Iran) b etween $10^{\text {th }}$ April 2020- $9^{\text {th }}$ March, 2021. All patients were diagnosed as stated by World Health Organization interim guidance (17). The patients with severe COVID-19 was confirmed by at least one of the following creteria: respiratory rate $\geq 30 / \mathrm{min}$; blood oxygen saturation $\leq 93 \%$; ratio of partial pressure of oxygen in arterial blood to the inspired oxygen fraction $(\mathrm{PaO} 2 \mathrm{FiO} 2)<300$; lung infiltrates present on $>50 \%$ of the lung field (18). Eight healthy age-matched controls were also recruited. This study was approved by Masih Daneshvari Hospital ethical committee (IR.SBMU.NRITLD.REC.1399.122).

\section{Data collection}

The clinical records of patients were collected from electronic medical records from Masih Daneshvari Hospital. The information recorded included demographic data, medical history, underlying comorbidities, symptoms, signs, laboratory findings; chest computed tomographic (CT) scans, and treatment 
measures including antiviral therapy, corticosteroid therapy, respiratory support and kidney replacement therapy.

\section{Laboratory examination of blood samples}

Whole blood samples containing anti-coagulant EDTA $(3 \mathrm{ml})$ and with citrate $(3 \mathrm{ml})$ or no anticoagulant (3ml) were obtained from all participants upon admission. Tubes containing blood without anticoagulant were centrifuged, the serum separated and stored at $-80^{\circ} \mathrm{C}$ for IL-8 measurement. Serum tests including kidney and liver function tests: creatinine kinase-muscle/brain activity (CK-MB), lactate dehydrogenase (LDH), C-reactive protein (CRP), ferritin, creatine phosphokinase (CPK), and the international normalized ratio (INR) were also performed. The erythrocyte sedimentation ratio was determined in citrate-treated whole blood samples.

\section{Cell staining and flow cytometry}

Three $\mathrm{ml}$ whole blood in EDTA were obtained from all participants and MDSCs were analysed by flow cytometry (FACS Calibour, BD, USA). Briefly, blood samples were then stained with anti-CD11b APC (BD Biosciences, CA, USA), anti-HLA-DR PE (eBioscience, San Diego, CA, USA), anti-CD14 PerCP-cy5.5 (eBioscience) and anti-CD15 FITC (BD Biosciences) for $30 \mathrm{~min}$ in the dark as described before $(19,20)$. Cells were then washed and suspended in FACS buffer before 20,000 events were analysed by FACS. The gating strategy was CD11b+/HLA-DR-/dim and within this population CD14+/CD15- cells and CD14-/CD15+ were identified as described previously $(19,20)$. Flow cytometry data was subsequently analysed by FlowJO-V10 software (USA) and reported as the frequency (percentage) of the respective subset of leukocytes.

\section{Measurement of IL-8}

Serum concentrations of IL-8 were measured by linked immunosorbent assay (ELISA) (BD Biosciences, CA, USA) as described in manufacturer data sheet.

\section{Statistical analysis}

Data analysis was performed using the SPSS software version 16.0 and Graph Pad Prism software version 6 . Results were reported as the mean \pm standard deviation (SD). The measurement data between two groups were analyzed using Student's $t$-test. The non-parametric Mann-Whitney $U$ test was used for nonnormally distributed variables. Difference among multiple groups was compared using one-way analysis of variance (ANOVA), $p<0.05$ was considered as statistically significant.

\section{Results}

\section{Demographic information of patients with COVID-19 and healthy control subjects}

The demographic information of the participants are shown in Table 1.The serum levels of ESR, CRP, LDH, Troponin, and MB activity between ICU (ventilated and non-ventilated) and non-ICU moderate COVID-19 patients didn't show any significant differences. However, CPK was higher in ICU patients (ventilated and non-ventilated) than non-ICU moderate patients $(P=0.01)$. (Table 1$)$. 
Table 1

The demographic data and biochemical characters of participants.

\begin{tabular}{|c|c|c|c|c|c|c|}
\hline & S (ICU) & & M (Non-ICU) & $\mathrm{HC}$ & $P$ value & \\
\hline & V & NV & $N=13$ & $N=8$ & ICU & V vs. NV vs. M \\
\hline & $N=8$ & $N=29$ & & & Vs. N-ICU & \\
\hline Age, years & $62.1 \pm 9.5$ & $58.3 \pm 13.2$ & $50.0 \pm 16.8$ & $40.1 \pm 10$ & 0.04 & 0.10 \\
\hline Female, N (\%) & $5(62.5)$ & $13(44.8)$ & $7(53.8)$ & $1(12.5)$ & - & - \\
\hline Male, N (\%) & $3(37.5)$ & $16(55.2)$ & $6(46.2)$ & $7(87.5)$ & - & - \\
\hline \multirow[t]{2}{*}{ ESR $(\mathrm{mm} / \mathrm{hr})$} & $52.0 \pm 31.9$ & $35.3 \pm 29.1$ & $44.0 \pm 37.3$ & - & 0.69 & 0.46 \\
\hline & $N=7$ & $N=21$ & $N=12$ & & & \\
\hline \multirow[t]{2}{*}{$\mathrm{CRP}(\mathrm{mg} / \mathrm{l})$} & $26.7 \pm 12.4$ & $40.6 \pm 25.6$ & $40.0 \pm 19.11$ & - & 0.91 & 0.56 \\
\hline & $N=4$ & $N=22$ & $N=4$ & & & \\
\hline \multirow[t]{2}{*}{ LDH (U/L) } & $677.1 \pm 459.1$ & $577.1 \pm 253.6$ & $492.9 \pm 124.4$ & - & 0.27 & 0.37 \\
\hline & $N=7$ & $N=26$ & $N=11$ & & & \\
\hline \multirow[t]{2}{*}{ Troponin (pg/ml) } & $0.02 \pm 0.0$ & $0.11 \pm 0.43$ & $0.02 \pm 0.0$ & - & 0.74 & 0.87 \\
\hline & $N=4$ & $N=22$ & $N=3$ & & & \\
\hline \multirow[t]{2}{*}{ CPK (U/L) } & $246.1 \pm 301.6$ & $215.4 \pm 295.9$ & $85.1 \pm 63.23$ & - & 0.01 & 0.35 \\
\hline & $N=7$ & $N=26$ & $N=10$ & & & \\
\hline \multirow[t]{2}{*}{ D-Dimer (ng/ml) } & $556.5 \pm 456.0$ & $1167.8 \pm 1351.1$ & $3945.0 \pm 4320.4$ & - & 0.52 & 0.06 \\
\hline & $N=2$ & $N=22$ & $N=2$ & & & \\
\hline \multirow[t]{2}{*}{ CK-MB Activity (U/L) } & $45.6 \pm 36.6$ & $44.7 \pm 48.1$ & $40.0 \pm 16.9$ & - & 0.88 & 0.98 \\
\hline & $N=3$ & $N=19$ & $N=2$ & & & \\
\hline \multirow[t]{2}{*}{02 Saturation \% } & $87.3 \pm 7.8$ & $65.5 \pm 23.2$ & $75.0 \pm 24.4$ & - & 0.58 & 0.27 \\
\hline & $N=3$ & $N=22$ & $N=4$ & & & \\
\hline \multirow[t]{2}{*}{ INR } & $1.1 \pm 0.05$ & $1.1 \pm 0.12$ & $1.1 \pm 0.13$ & - & 0.43 & 0.60 \\
\hline & $N=4$ & $N=23$ & $N=4$ & & & \\
\hline
\end{tabular}

*Values were presented as Mean \pm SD. $p<0.05$ was considered significant

$\mathrm{N}$ numbers are for whole group unless otherwise indicated.

Abbreviations: CK-MB: creatinine kinase-muscle/brain; CPK: creatine phosphokinase CRP: C-reactive protein; ESR: erythrocyte sedimentation rate; INR: international normalized ratio; LDH: lactate dehydrogenase;

HC: Healthy control; M: Moderate; S: Severe; ICU: Intensive care unit; NV: Non-ventilated; V: Ventilated

\section{MDSC analysis}

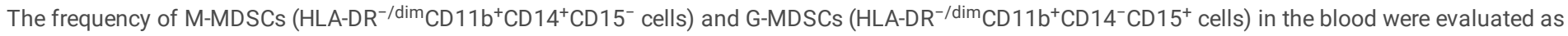
described previously (19). The gating strategy way and the frequency of G-MDSC and M-MDSC cells in representative healthy control subjects and COVID-19 patients of differing severity are shown in Fig. 1. There was a significantly greater frequency of M-DSCs (Fig. 2A, Table 2) and G-MDSCs (Fig. 2B, Table 2) in all COVID-19 patients as a group compared to healthy subjects $(P \leq 0.0001, P \leq 0.0001$, respectively). 
Table 2

The frequency of MDSCs and IL-8 levels in serum of COVID-19 patients and healthy controls

\begin{tabular}{|llll|}
\hline & COVID-19 Patients & HC & P value \\
\hline M-MDSC (\%) & $12.7 \pm 13.3$ & $0.19 \pm 0.20$ & $\leq 0.0001$ \\
& $\mathrm{~N}=48$ & $\mathrm{~N}=8$ & \\
G-MDSC (\%) & $15.8 \pm 12.6$ & $0.35 \pm 0.40$ & $\leq 0.0001$ \\
& $\mathrm{~N}=50$ & $\mathrm{~N}=8$ & \\
\hline IL-8 & $6.4 \pm 7.8$ & $0.10 \pm 0.0$ & 0.03 \\
& $\mathrm{~N}=32$ & $\mathrm{~N}=8$ & \\
Values were presented as Mean \pm SD. $\mathrm{p}<0.05$ was considered significant \\
HC; Healthy control & & \\
\hline
\end{tabular}

Next we analysed the M-MDSC and G-MDSC cells in moderate and severe COVID-19 patients. There are significant differences in the frequency of M-MDSCs between moderate, non-ventilate and ventilated patients ( $P=0.03$ )(Fig. 2C, Table 3). In addition, there was a significant increase in M-MDSC frequency in severe COVID-19 patients who were not ventilated compared to moderate patients $(P=0.004)$ (Fig. $2 \mathrm{C}$, Table 3 ). In contrast, any significant differences were found between ventilated and non-ventilated patients in the frequency of M-MDSC (Fig. 2C). Furthermore, moderate and severe COVID-19 patients have a significantly higher frequency of M-MDSC compared with HC (Fig. 2C, Table 3).

Table 3

The frequency of MDSCs and serum IL-8 levels in severe COVID-19 patients according to ICU status

\begin{tabular}{|c|c|c|c|c|c|c|c|c|c|c|c|}
\hline & \multirow[t]{2}{*}{$\mathrm{HC}$} & \multirow[t]{2}{*}{$M$} & \multicolumn{3}{|l|}{$S$} & \multicolumn{6}{|l|}{$P$ value } \\
\hline & & & NV & V & $\begin{array}{l}\text { M vs. } \\
\text { HC }\end{array}$ & $\begin{array}{l}\text { NV vs. } \\
\text { HC }\end{array}$ & $\begin{array}{l}\text { Vvs. } \\
\text { HC }\end{array}$ & $\begin{array}{l}\text { Vvs. NV vs. } \\
M\end{array}$ & $\begin{array}{l}\text { NV vs. } \\
\text { M }\end{array}$ & $\begin{array}{l}\text { Vvs. } \\
M\end{array}$ & $\begin{array}{l}\text { NV vs. } \\
\text { V }\end{array}$ \\
\hline \multirow{2}{*}{$\begin{array}{l}\text { M-MDSC } \\
(\%)\end{array}$} & \multirow{2}{*}{$\begin{array}{l}0.19 \pm \\
0.20\end{array}$} & $5.4 \pm 4.8$ & $\begin{array}{l}16.8 \pm \\
15.8\end{array}$ & $10.3 \pm 6.4$ & \multirow[t]{2}{*}{0.0006} & \multirow[t]{2}{*}{$\leq 0.0001$} & \multirow[t]{2}{*}{0.0002} & \multirow[t]{2}{*}{0.03} & \multirow[t]{2}{*}{0.004} & \multirow[t]{2}{*}{0.06} & \multirow[t]{2}{*}{0.43} \\
\hline & & $N=13$ & $N=27$ & $N=8$ & & & & & & & \\
\hline \multirow[t]{2}{*}{$\begin{array}{l}\text { G-MDSC } \\
(\%)\end{array}$} & \multirow[t]{2}{*}{$\begin{array}{l}0.35 \pm \\
0.40\end{array}$} & $\begin{array}{l}11.8 \pm \\
11.6\end{array}$ & $\begin{array}{l}17.6 \pm \\
13.6\end{array}$ & $\begin{array}{l}15.6 \pm \\
10.0\end{array}$ & \multirow[t]{2}{*}{$\leq .0001$} & \multirow[t]{2}{*}{$\leq 0.0001$} & \multirow[t]{2}{*}{0.0002} & \multirow[t]{2}{*}{0.40} & \multirow[t]{2}{*}{0.19} & \multirow[t]{2}{*}{0.46} & \multirow[t]{2}{*}{0.70} \\
\hline & & $N=13$ & $N=29$ & $N=8$ & & & & & & & \\
\hline \multirow[t]{2}{*}{ IL-8 } & \multirow[t]{2}{*}{$\begin{array}{l}0.10 \pm \\
0.00\end{array}$} & & & \multirow{2}{*}{$\begin{array}{l}15.7 \pm \\
16.7 \\
N=5\end{array}$} & \multirow[t]{2}{*}{0.02} & \multirow[t]{2}{*}{$\leq 0.0001$} & \multirow[t]{2}{*}{0.02} & \multirow[t]{2}{*}{0.005} & \multirow[t]{2}{*}{0.01} & \multirow[t]{2}{*}{0.008} & \multirow[t]{2}{*}{0.04} \\
\hline & & $N=10$ & $N=17$ & & & & & & & & \\
\hline \multicolumn{12}{|c|}{ Values were reported as Mean $\pm S D$. $p<0.05$ was considered significant. } \\
\hline \multicolumn{12}{|c|}{ Abbreviations: } \\
\hline \multicolumn{12}{|c|}{ HC: Healthy Controls } \\
\hline M: Modera & & & & & & & & & & & \\
\hline S: Severe & & & & & & & & & & & \\
\hline V: Ventilate & & & & & & & & & & & \\
\hline NV: Non Ve & ated & & & & & & & & & & \\
\hline
\end{tabular}

No significant differences in G-MDSC cell frequencies were found between moderate and severe COVID-19 patients although all COVID-19 groups had a higher frequency than observed for HC (Fig. 2D, Table 3).

\section{IL-8 levels}

IL-8 levels in the serum of COVID-19 patients (moderate and severe) was significantly higher than in healthy control subjects ( $\mathrm{P}=0.03)(\mathrm{Fig}$. $3 \mathrm{~A}$, Table 2$)$. In addition, IL-8 levels in serum were significantly higher in severe COVID-19 patients on ventilation compared to those who were not ventilated $(P=0.04)$ and in moderate patients $(P=0.008)$ (Fig. 3B, Table 3). Systemic IL-8 levels were higher in non-ventilated patients than in patients with moderate COVID-19 $(P=0.01)$ (Fig. 3B, Table 3). 
The relationships between M-MDSCs and G-MDSCs frequency and IL-8 concentration with serum biochemical markers LDH, ESR, CRP, troponin, CPK, CK-MB activity and D-dimer, INR, age and arterial 02 saturation were evaluated. G-MDSC frequency correlated negatively with INR $(r=-0.39, P=0.02)$ and no other significant correlations were observed (Table 4).

Table 4

Correlation analysis between M-MDSC, G-MDSC, IL-8 and other factors in COVID-19 patients

\begin{tabular}{|c|c|c|c|c|c|c|c|c|c|c|c|c|c|c|c|c|c|c|}
\hline & \multicolumn{2}{|l|}{ ESR } & \multicolumn{2}{|l|}{ CRP } & \multicolumn{2}{|l|}{ LDH } & \multicolumn{2}{|l|}{ CPK } & \multicolumn{2}{|c|}{ Troponin } & \multicolumn{2}{|c|}{ CK-MB } & \multicolumn{2}{|c|}{02 sat\% } & \multicolumn{2}{|c|}{ D-Dimer } & \multicolumn{2}{|l|}{ INR } \\
\hline & $\mathbf{r}$ & $p$ & $\mathbf{r}$ & $p$ & $\mathbf{r}$ & p & $r$ & $p$ & $\mathbf{r}$ & $p$ & $\mathbf{r}$ & p & $r$ & p & $\mathbf{r}$ & $\mathbf{p}$ & $r$ & $p$ \\
\hline $\begin{array}{l}\text { M- } \\
\text { MDSC }\end{array}$ & 0.01 & 0.95 & 0.004 & 0.98 & -0.04 & 0.75 & -0.10 & 0.52 & -0.10 & 0.59 & -0.12 & 0.58 & -0.30 & 0.12 & -0.26 & 0.21 & -0.12 & 0.53 \\
\hline $\begin{array}{l}\text { G- } \\
\text { MDSC }\end{array}$ & 0.05 & 0.74 & 0.12 & 0.51 & 0.14 & 0.33 & -0.09 & 0.55 & -0.20 & 0.29 & -0.31 & 0.12 & -0.10 & 0.58 & -0.27 & 0.17 & -0.39 & 0.02 \\
\hline IL-8 & 0.008 & 0.96 & -0.23 & 0.27 & 0.14 & 0.45 & 0.10 & 0.57 & 0.11 & 0.60 & 0.22 & 0.28 & 0.17 & 0.41 & -0.26 & 0.27 & -0.15 & 0.46 \\
\hline
\end{tabular}

r: Pearson correlation coefficient, p: p-value

Abbreviations: CK-MB: creatinine kinase-muscle/brain; CPK: creatine phosphokinase CRP: C-reactive protein; ESR: erythrocyte sedimentation rate; INR: interna lactate dehydrogenase

\section{Discussion}

We demonstrated that M-MDSCs and G-MDSCs frequencies were increased in the peripheral blood of COVID-19 patients from Iran compared to healthy subjects. There was a significant elevated in the M-MDSCs frequency in non-ventilated compared to moderate COVID-19 patients. Overall, serum IL-8 levels were significantly higher in COVID-19 patients compared to healthy controls and in severe ventilated COVID-19 patients compared to non-ventilated COVID-9 patients.

MDSCs are immature myeloid cells that suppress T cell responses (12). The IL-8 receptors CXCR1 and CXCR2 express on the surface of M-MDSCs and GMDSCs, therefore, IL-8 may attract peripheral MDSCs to tumour sites (21). In addition, higher serum IL-8 levels have been related to the severity of COVID-19 patients (22) although one study has reported that blood levels of IL-8 and MDSCs in ICU and non-ICU COVID-19 patients were similar (23). Bourboulis and colleagues showed that COVID-19 patients with severe respiratory failure presented with a lower percentage of HLA-DR on CD14 monocytes (24). Furthermore CD14 + HLA-DR ${ }^{\text {low }}$ cells were seen in severe COVID-19 patients and associated immune dysregulation (24). This MDSC expansion seen may account for the T cells dysregulation, particularly that of CD8 T cells, seen in COVID-19 patients who develop acute respiratory distress syndrome (25).

Agrati and co-workers showed that the percentage of G-MDSCs was increased in severe and mild COVID-19 patients (22). In contrast, COVID-19 patients during the later convalescent phase of severe disease showed a decreased frequency of MDSC cells which was linked to higher systemic levels of IL-8, IL-1 $\beta$ and TNF- $\alpha$ and reduced TGF- $\beta$ levels $(3,22,26)$. Systemic IL- 8 levels positively correlated with the duration of COVID-19 and is an important neutrophil chemoattractant with neutrophilia and the neutrophils/lymphocyte ratio (NLR) being markers of SARS-COV-2 infection (27).

We have demonstrated G-MDSC cells frequency increased in moderate and severe COVID-19 patients and healthy subjects but we did not find any significant difference between moderate and severe patients. In a study from Italy, PMN-MDSC frequency was higher in severe COVID-19 patients who died upon admission to hospital compared to those who survived (28). This study also reported that plasma IL-8 levels were also higher in non-survivors than in survivors upon admission, and decreased to levels comparable to those of survivors at later time points (28). However, the higher serum levels of IL-8 in ventilated COVID-19 patients in our study are consistent with other reports (28). We are unable to account for the discrepancy in the frequency of G-MDSC cells in ventilated severe COVID-19 patients from Iran compared to Italy but suggest that this may reflect differences in treatment and/or ethnicity between subjects in Iran and Italy or possibly the number of subjects studied. Overall, our data does not support the hypothesis that MDSCs are a predictor of COVID-19 outcomes.

In the current study we have also seen a difference in IL-8 levels between ventilated and non-ventilated severe COVID-19 patients and that both groups had higher IL-8 levels than in moderate disease and in healthy controls. Furthermore, there were no differences in peripheral blood G-MDSC frequency between COVID-19 patients with different severities although they were all groups of patients were higher than healthy control subjects. In contrast, the frequency of MMDSC in the blood of non-ventilated severe COVID-19 patients was higher than patients with moderate disease.

We did not find any link between systemic IL-8 levels and the proportion of MDSC cells in blood. This suggests that either other factors are responsible for the production of MDSCs in these patients or that the enhanced blood levels of IL-8 reflect much higher levels in the lung and other COVID-19-infected tissues and this results in margination to these tissues. This may be even more evident in patients with very severe disease who are on ventilation where margination of M-MDSCs from the blood to the lung or kidney results in suppression of the local immune response. Future studies are required using matched peripheral blood and lung samples, for example, to determine whether this is indeed the case. A recent study indicated that M-MDSC frequency is enhanced in blood but not in the upper airways of COVID-19 patients (16).

In HIV-1 patients, the expansion of MDSCs promotes the differentiation of regulatory T cells and thereby control T cell differentiation and function (29). Thus, in HIV-1 patients MDSCs play a role in countering viral persistence and may suggest a new immunotherapeutic strategy against human viral diseases (29). Moreover, increased levels of M-MDSCs strongly correlates with a worse outcome in septic shock (30). MDSCs play a dual role in patients with sepsis (31) 
being beneficial by reducing inflammation during early stage disease stage whilst in the latter stages of disease they are able to induce long term immunosuppression $(22,31)$.

In summary, our data in Iranian patients are in line with other studies showing increased IL-8 in the peripheral blood of COVID-19 patients and that higher expression was associated with worse clinical outcomes. This may lead to the expansion and recruitment of MDSC cells and that targeting this cytokineMDSC network may provide a new approach to improve clinical outcomes of COVID-19 patients.

\section{Declarations}

\section{ETHICS STATEMENT}

This study approved by Masih Daneshvari Hospital ethical Committee. The participants signed informed consent to participate in the study.

\section{AUTHOR CONTRIBUTIONS}

EM, NKD and NDR did experiments. EM and NKD did statistical analysis. EM wrote the first draft of paper. MM, AB, JG revised the first draft of paper. HJ confirmed patient's demographic information and revised the paper. IMA approved the final version of paper. All authors contributed to the article and approved the submitted version.

\section{FUNDING}

This study was supported by internal funds.

\section{CONFLICT OF INTEREST}

The authors confirm that there are no conflicts of interests.

\section{ACKNOWLEDGMENTS}

We acknowledge all study participants whom are alive or died due to the COVID-19 disease.

\section{References}

1. Le Bert N, Tan AT, Kunasegaran K, Tham CY, Hafezi M, Chia A, et al. SARS-CoV-2-specific T cell immunity in cases of COVID-19 and SARS, and uninfected controls. Nature. 2020;584(7821):457-62.

2. Mortaz E, Tabarsi P, Varahram M, Folkerts G, Adcock IM. The Immune Response and Immunopathology of COVID-19. Front Immunol. 2020;11:2037. PubMed PMID: 32983152. Pubmed Central PMCID: 7479965.

3. Mortaz E, Bassir A, Dalil Roofchayee N, Dezfuli NK, Jamaati H, Tabarsi P, et al. Serum cytokine levels of COVID-19 patients after 7 days of treatment with Favipiravir or Kaletra. International immunopharmacology. 2021 Apr;93:107407. PubMed PMID: 33631512. Pubmed Central PMCID: 7826095.

4. F. Zhou TY, R. Du, G. Fan, Y. Liu, Z. Liu, et al. Clinical course and risk factors for mortality of adult inpatients with COVID-19 in Wuhan, China: a retrospective cohort study. Lancet. 2020;395(10229):1054-62.

5. Sette A, Crotty S. Pre-existing immunity to SARS-CoV-2: the knowns and unknowns. Nature Reviews Immunology. 2020;20(8):457-8.

6. Nikolich-Zugich J, Knox KS, Rios CT, Natt B, Bhattacharya D, Fain MJ. SARS-CoV-2 and COVID-19 in older adults: what we may expect regarding pathogenesis, immune responses, and outcomes. Geroscience. 2020:1-10.

7. Agrati C, Sacchi A, Bordoni V, Cimini E, Notari S, Grassi G, et al. Expansion of myeloid-derived suppressor cells in patients with severe coronavirus disease (COVID-19). Cell Death \& Differentiation. 2020:1-12.

8. Dezfuli N, Adcock I, Montazami N, Mortaz E, Velayati A. Update on Immunology of COVID-19 Disease and Potential Strategy for Controlling Tanaffos 2020;19(4):274-90

9. Gabrilovich DI, Nagaraj S. Myeloid-derived suppressor cells as regulators of the immune system. Nature reviews immunology. 2009;9(3):162-74.

10. Ostrand-Rosenberg S, Sinha P. Myeloid-derived suppressor cells: linking inflammation and cancer. The Journal of Immunology. 2009;182(8):4499-506.

11. Seyed Sajjad Zadian IMA, Babak Salimi, Esmaeil Mortaz, . Circulating Levels of Monocytic Myeloid-Derived Suppressor Cells (M-MDSC) and CXCL-8 in Non-Small Cell Lung Cancer (NSCLC). Tanaffos. 2021;20(1):1-7.

12. Gabrilovich DI, Nagaraj S. Myeloid-derived suppressor cells as regulators of the immune system. Nature reviews Immunology. 2009 Mar;9(3):162-74. PubMed PMID: 19197294. Pubmed Central PMCID: 2828349.

13. Sinha P CV, Bunt SK, Albelda SM, Ostrand-Rosenberg S. . Crosstalk between myeloidderived suppressor cells and macrophages subverts tumor immunity toward a type 2 response. Journal of immunology. 2007;179:977-83.

14. Murdoch C MM, Coffelt SB, Lewis CE. The role of myeloid cells in the promotion of tumour angiogenesis. Nat Rev Cancer. 2008;8:618-31.

15. Guo PL, Li LH, Li WL, Zhao JC, Hu FY, Zhang FC, et al. The clinical significance of myeloid-derived suppressor cells in dengue fever patients. BMC Infect Dis. 2019 Nov 1;19(1):926. PubMed PMID: 31675923. Pubmed Central PMCID: 6824033.

16. Falck-Jones S, Vangeti S, Yu M, Falck-Jones R, Cagigi A, Badolati I, et al. Functional monocytic myeloid-derived suppressor cells increase in blood but not airways and predict COVID-19 severity. J Clin Invest. 2021 Jan 25:DOI:10.1172/JCI144734. PubMed PMID: 33492309. 
17. World Health 0 . Clinical management of severe acute respiratory infection (SARI) when COVID-19 disease is suspected. Interim guidance. Pediatria i Medycyna Rodzinna. 2020;16(1):9-26.

18. Lee DW, Gardner R, Porter DL, Louis CU, Ahmed N, Jensen M, et al. Current concepts in the diagnosis and management of cytokine release syndrome. Blood. 2014;124(2):188-95.

19. Yamauchi Y, Safi S, Blattner C, Rathinasamy A, Umansky L, Juenger S, et al. Circulating and Tumor Myeloid-derived Suppressor Cells in Resectable NonSmall Cell Lung Cancer. Am J Respir Crit Care Med. 2018 Sep 15;198(6):777-87. PubMed PMID: 29617574.

20. Apodaca MC, Wright AE, Riggins AM, Harris WP, Yeung RS, Yu L, et al. Characterization of a whole blood assay for quantifying myeloid-derived suppressor cells. Journal for immunotherapy of cancer. 2019 Aug 28;7(1):230. PubMed PMID: 31462270. Pubmed Central PMCID: 6714080.

21. Tobin RP, Jordan KR, Kapoor P, Spongberg E, Davis D, Vorwald VM, et al. IL-6 and IL-8 Are Linked With Myeloid-Derived Suppressor Cell Accumulation and Correlate With Poor Clinical Outcomes in Melanoma Patients. Frontiers in oncology. 2019;9:1223. PubMed PMID: 31781510. Pubmed Central PMCID: 6857649.

22. Agrati C, Sacchi A, Bordoni V, Cimini E, Notari S, Grassi G, et al. Expansion of myeloid-derived suppressor cells in patients with severe coronavirus disease (COVID-19). Cell death and differentiation. 2020 Nov;27(11):3196-207. PubMed PMID: 32514047. Pubmed Central PMCID: 7278239.

23. Bordoni V, Sacchi A, Cimini E, Notari S, Grassi G, Tartaglia E, et al. An Inflammatory Profile Correlates With Decreased Frequency of Cytotoxic Cells in Coronavirus Disease 2019. Clinical infectious diseases : an official publication of the Infectious Diseases Society of America. 2020 Nov 19;71(16):2272-5. PubMed PMID: 32407466. Pubmed Central PMCID: 7239202.

24. Giamarellos-Bourboulis EJ NM, Rovina N, et al. . . Complex Immune Dysregulation in COVID-19 Patients with Severe Respiratory Failure. Cell Host Microbe 2020;270:992-1000.

25. Reizine F, Lesouhaitier M, Gregoire M, Pinceaux K, Gacouin A, Maamar A, et al. SARS-CoV-2-Induced ARDS Associates with MDSC Expansion, Lymphocyte Dysfunction, and Arginine Shortage. J Clin Immunol. 2021 Apr;41(3):515-25. PubMed PMID: 33387156. Pubmed Central PMCID: 7775842.

26. Mortaz E, Tabarsi P, Jamaati H, Dalil Roofchayee N, Dezfuli N, Hashemian S, et al. Increased serum levels of soluble TNF-a receptor is associated with mortality of ICU COVID-19 patients Front Immunol. 2021.

27. Ma A, Zhang L, Ye X, Chen J, Yu J, Zhuang L, et al. High Levels of Circulating IL-8 and Soluble IL-2R Are Associated With Prolonged IIIness in Patients With Severe COVID-19. Front Immunol. 2021;12:626235. PubMed PMID: 33584733. Pubmed Central PMCID: 7878368.

28. Sacchi A, Grassi G, Bordoni V, Lorenzini P, Cimini E, Casetti R, et al. Early expansion of myeloid-derived suppressor cells inhibits SARS-CoV-2 specific T-cell response and may predict fatal COVID-19 outcome. Cell death \& disease. 2020 Oct 27;11(10):921. PubMed PMID: 33110074. Pubmed Central PMCID: 7590570.

29. Wang L, Zhao J, Ren JP, Wu XY, Morrison ZD, Elgazzar MA, et al. Expansion of myeloid-derived suppressor cells promotes differentiation of regulatory $T$ cells in HIV-1+ individuals. Aids. 2016 Jun 19;30(10):1521-31. PubMed PMID: 26959508. Pubmed Central PMCID: 4889474.

30. Waeckel L VF, Gossez M, Monard C, Rimmelé T, Monneret G. . Delayed persistence of elevated monocytic MDSC associates with deleterious outcomes in septic shock: a retrospective cohort study. . Crit Care 2020;24:132.

31. Schrijver IT, Theroude C, Roger T. Myeloid-Derived Suppressor Cells in Sepsis. Front Immunol. 2019;10:327. PubMed PMID: 30873175. Pubmed Central PMCID: 6400980.

\section{Figures}


Fig. 1
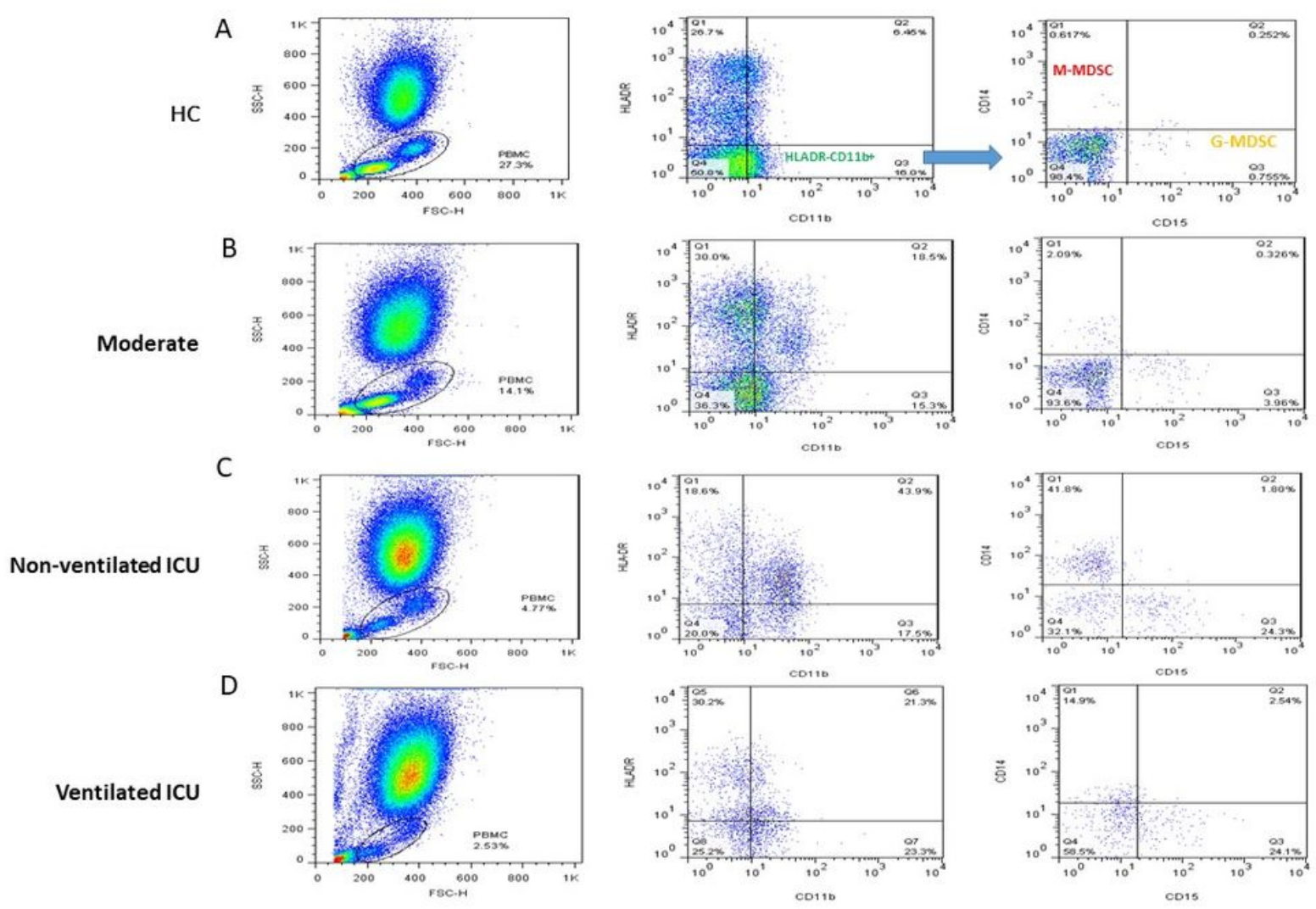

\section{Figure 1}

Gating strategy for M-MDSC and G-MDSC cells. Representative dot plots of flow cytometry data M-MDSCs (HLA-DR-/dimCD11b+CD14+CD15- cells) and GMDSCs (HLA-DR-/dimCD11b+CD14-CD15+ cells) in the blood of a HC (A) and moderate (B) non-ventilated ICU (C) and ventilated ICU (D) patients frequency of cells are indicated in the text boxes in the top left (M-MDSC) and bottom right (G-MDSC) panels.

Fig. 2

A

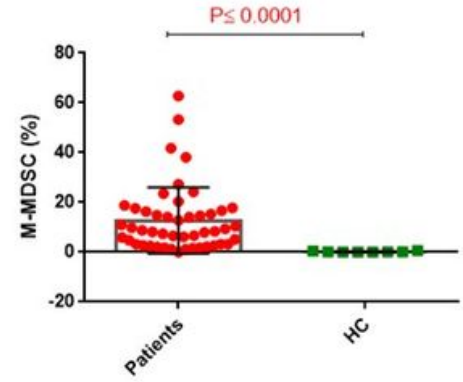

C

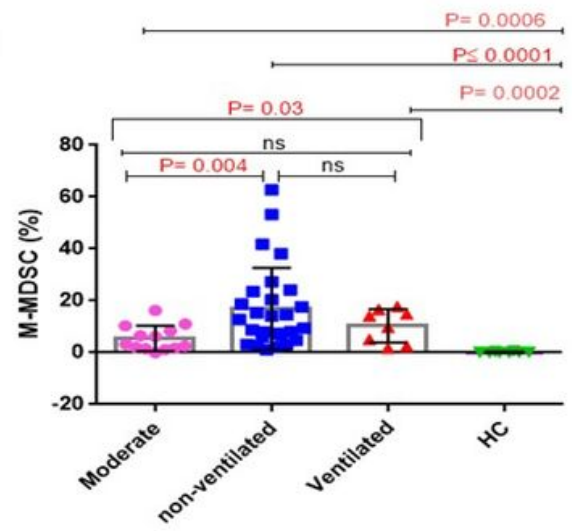

B

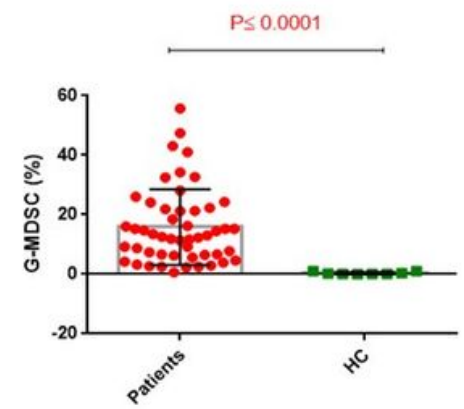

D
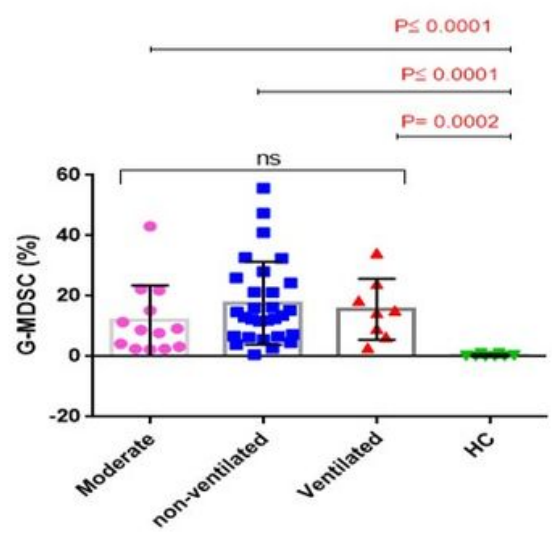

Figure 2 
Fig. 3

A

B

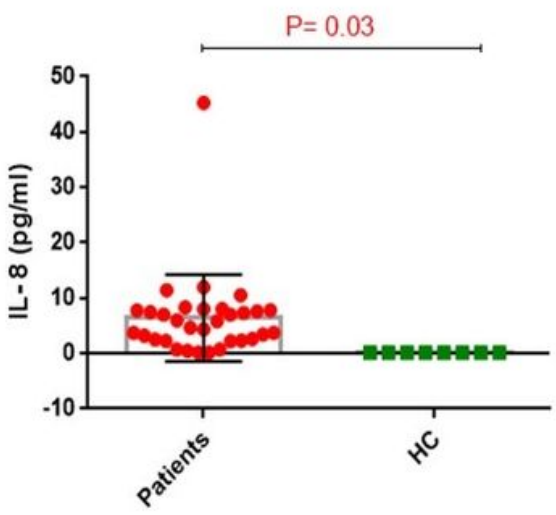

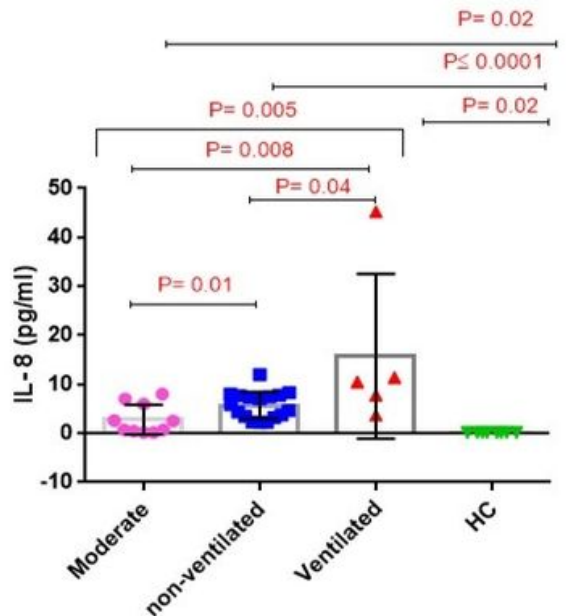

Figure 3

Please see the Manuscript file for the complete figure caption. 